\title{
Synchronous Nodules with Dominant Lesion(s)
}

National Cancer Institute

\section{Source}

National Cancer Institute. Synchronous Nodules with Dominant Lesion(s). NCI

Thesaurus. Code C139573.

A finding of multiple pulmonary nodules in which radiologic imaging demonstrates the presence of a dominant lesion. 